\title{
Disquieting presences: the ambiguity and indeterminacy of Maurice Nio's architecture
}

\author{
Silvio Carta ${ }^{*}$ (1)
}

\begin{abstract}
Background: In recent years, Dutch architect Maurice Nio has built an array of projects in the Netherlands, which have generally been considered within the spectrum of the Superdutch phenomenon, and more broadly, within Iconic Architecture. Seemingly, to his Dutch colleagues, Nio's work is on the track of liberating architecture from the burden of cultural responsibilities (Ibelings Supermodernism: Architecture in the age of globalization: Nai Uitgevers Pub, 1998), yet it evinces significant differences from other work in that vein.

Methods: Nio's projects are compared with Jencks' phenomenology of iconic architecture (Jencks The iconic building: Rizzoli New York, 2005), in order to demonstrate the importance and peculiarity of Nio's work within the context of Iconic Architecture and the Superdutch period, and the extent to which his work can be considered different.

Results: This article argues that Nio's architecture is not based on the production of outstanding shapes (Lootsma SuperDutch Afterthoughts Post. Rotterdam. Rotterdam: 010 Publisher, 2001), or the clever interpretation of a given program (Betsky Reading MVRDV: NAi 2003), but on the creation of disquieting presences in the built environment. Most of his work consists of pieces of architecture each of which has its own name, character and identity and seems to rely on disrupting the expected and disturbing the quiet.
\end{abstract}

Conclusions: This paper examines Nio's work, with particular attention to three case studies, in order to generate a series of qualitative characteristics that define his idiosyncratic architecture.

Keywords: Dutch architecture, Superdutch, Supermodernism, Iconic architecture, Maurice Nio

\section{Surmodernité and iconic architecture}

The emergence of ambiguity as a necessary and positive element of the observation of reality can be framed through the work of several seminal texts, including those of British theorist Terry Eagleton (1996), Fredric Jameson (1991) and David Harvey (1989). The extensive body of work in a variety of cultural fields-from philosophy to sociology, and from art to geography, concerning what by the end of the nineties had been called Postmodernism, had raised sufficient doubts concerning more stable views of the world that much of society had become ready to see the world as continuously changing. Given an uncertain reality, the relationship between reality and its manifestations became a spiky question-if not an insoluble one. Several

*Correspondence: s.carta@herts.ac.uk School of Creative Arts, University of Hertfordshire, College Lane Campus, Herts AL10 9AB, UK architectural works may be said to epitomize this approach to the world; amongst many, Rossi's Città Analoga clearly denotes that strained relationship, by referring to a city that is perceivable only as an analogical sequence of facts. The Città Analoga does not allow for explanation: "This work [the text along the large panel of the "analogous city", $\mathrm{a} / \mathrm{n}]$ is not the explanation of the analogous city because we do not believe that explanations exist" (Rossi 1976). In thus describing the indescribable, Rossi referred to Canaletto's Venetian Capricci, emphasizing the importance of depicting the same universal city (Venice in this case) in a subjective manner-that is to say, by creating a comprehensive picture of the city through a collage of its buildings and public spaces; reshuffling the recognizable elements of the built environment through each viewer's subjectivity. This operation resulted in an ambiguous image of the city, running against the idea of the existence of a unique and mono-interpretable built environment. 
In architectural literature, Bernard Tschumi's (1989) ${ }^{1}$ essay "De-, Dis-, Ex-," describes a world where all manner of de-construction is possible and, somehow, needed, in epistemological terms. Tschumi's work, but also that of Koolhaas (1995) and Jencks (1978) amongst others, indicated how relatively easy it was for young architects to feel comfortable in a world composed of the doubts, contradictions and complexities of a society; or, more generally, they contributed to the depiction of a contemporary reality, not to be comprehended via the rules, categories or rigid explanations previously employed.

Ambiguity and indeterminacy as to shape, space and function first became an anthropological reality in the early nineties, as epitomised by the lucky neologism coined by Marc Augé: Non-Lieux (1992), and then began to affect urban awareness with Koolhaas' notion of genericness. In fact, in his essay "Generic City", Koolhaas (1995) introduced the term as a description of a contemporary city that Tschumi had appraised as "deregulated". Koolhaas' "generic" refers to that "general urban condition" which is "happening everywhere" and whose "very characterlessness provides the best context for living." ${ }^{3}$ Ambiguity, as the family of terms in which is embedded the idea of the impossibility of definitions of space, function or form in architecture, passed from being something to neglect (under Modern determinism), to a notion to be observed with curiosity and potential interest (in Postmodernism), to eventually being considered an actual diffused condition to depart from in new projects. "Generic" describes those places in which the (super)modern person gets lost ${ }^{4}$ or has the feeling of being nowhere. ${ }^{5}$ Genericness is thus a generally accepted condition for architects and users in the built environment. Paul Virilio was among the first intellectuals to sense this shift, describing it in terms of the change of the urban condition, from a planned system to a deregulated one (Tschumi 1989). In 1989, he described the contemporary city as "overexposed" ${ }^{\prime \prime}$ reflecting on the configuration and meaning of boundaries in cities of the time.

\footnotetext{
1 The date corresponds to "De-, Dis-, Ex-," Bernard Tschumi's essay, but it is also quite important to remember that on November 9 of the same year the Berlin Wall officially fell, initiating a reconfiguration of the world's arrangements and initiating a new balance among nations.

2 Bernard Tschumi, “De-, Dis-, Ex-," op.cit.

${ }^{3}$ See Koolhaas (1996).

${ }^{4}$ Cf. the film Crash, 2004, directed by Paul Haggis, and Concrete Island, a 1974 English novel by J. G. Ballard.

5 We might say "elsewhere.": cf. Marc Augé, “Near and Elsewhere," in Marc Augé, Non-Lieux, (1992)

6 The urban has lost its form, with the sole exception of the form image without dimension, the point or punctum which is everywhere, while the measurable length is nowhere. In the manner of the nodal or Pascalian mode, this centre which rejects all circumference and even the very concept of periphery is the uncertainty principle applied to the world geomorphological continuum. Paul Virilio, "The Overexposed City" ("La ville surexposée", 1983).
}

Charles Jencks was one of the first authors to try to depict the architects' reaction to genericness by calling for a "new genre" in the form of "expressive landmarks [...] challenging the previous tradition of the architectural monument" (Jencks 2005, p. 7). His book Iconic Architecture (Jencks 2005) drew a timeline of iconic presences along the entire history of architecture from the pyramids and the Colossus of Rhodes (third century BC) to the first "modern icons", namely Le Corbusier's Chapelle Notre-Dame-du-Haut in Ronchamp (1950-1955) or Bofill's fortress-like housing project Walden 7 (1972-1975), encompassing such milestones as Paris's Place de la Concorde or the Tour Eiffel. Jencks distinguishes architectural icons into "iconic icons" and "enigmatic signifiers": where the former is "a bizarre reduced image" and, similarly to an iconic sign, bears "similitude between visual images" (Jencks 2005, p. 28); the latter encompasses those projects resulting from an "absence of strong belief in any metanarrative, ideology, or religion [that] has characterized postmodern culture for several decades and is a strong motivation for the iconic building to become an enigma" (Jencks 2005, p. 195). Jencks' thesis is that, during the last few decades, enigmatic signifiers have gradually taken over the position of iconic icons (namely "traditional" iconic architecture) in cities, producing the plethora of landmarks nowadays broadly identified as iconic buildings. The two most successful iconic buildings are Foster's Swiss Re headquarters (London, 2004) and Gehry's Walt Disney Concert Hall (Los Angeles, 2003).

According to Jencks, it is possible to frame a sort of phenomenology to encompass the wide production of (successful) "enigmatic signifiers". Namely, they

- apply metaphors as a dominating aspect (Jencks 2005, p. 208)

- convey naturalistic and cosmic imagery (Ibidem, p. 208)

- embody cosmic references (ibidem, p. 209)

- provoke verbal evidence (ibidem, p. 179)

- are neither freeform, nor completely usual (ibidem, p. 185)

- have visual (layered) ambiguity (ibidem, p. 192)

- are fit for worship (replacing monuments/historical place of worship) (ibidem, p. 196, 203)

- work as (Eco's) "Open Work": They "channel understanding along certain avenues, but [do] not force those in search of the meaning down a single or oneway alley" (ibidem, p. 203).

\section{Maurice Nio}

Within the Supermodern/iconic scenario, and following what was by then called "the cultural component of architecture", the figure of Maurice Nio represents an

\footnotetext{
${ }^{7}$ During the 80s the Netherlands recognized the necessity of opening its archi-
} tecture to the "cultural component of architecture." Lootsma (2001, p. 116). 
original stance. In the latter half of the eighties, while still a student at the Faculty of Architecture at the Delft University of Technology, he made his position clear, bluntly, towards the architectural scene:

I wanted to be a film director, but stayed at the university. The first year I started as a regular student, following the prescribed program, but in the second year it became clear that architecture was merely about... designing buildings. The extra was maybe some kind of social sauce to distract one from the fact that it was an empty discipline. Nothing exciting. $^{8}$

The destabilising ideas of Postmodernism were evident in his lust for something outside the proposed disciplinary discourse: "It was impossible to "learn" architecture, not in the university, not from good architects outside of the university". ${ }^{\prime 9}$ Maurice Nio's reaction to the difficulties of understanding a continuously changing reality and producing architecture with a unique system of values would translate into an attempt to enlarge the range of elements in architecture, or, in other words, to mystify the given architectural setups of the time. The larger conceptual burden, at the time, was a notion, intended as a discipline, of a coherence to be pursued in every work of architecture. Against that conception, and partially according to Postmodern ideas, Nio went for ambiguity and unclarity: "An enormous weight fell off my shoulders-the weight of coherence [...] the desire for coherence is anywhere and always tangible, especially within the circle of writers, artists, architects, etc." ${ }^{10}$ Within the construction of a fragmented and elusive reality that other intellectuals were working on, ${ }^{11} \mathrm{Nio}$ speculated concerning consistency in the work of the architect: "Where most of the architects have managed to build a beautiful coherent style, with me, every project seems to erase the memory of the image of the previous one.".

Finally, Nio reached a conclusion which can be seen as a guideline he would follow in his subsequent work: " $I$ understood that coherence could not be found in style, form and the explicit, but in method, structure and the

\footnotetext{
${ }^{8}$ All quotes from Maurice Nio in this text, except those from the $N I O$ Architecten: 02 Design Peak, (2010) and from interviews with the author between December 2010 and January 2011.

${ }^{9}$ When Nio was a student, most architects and professors around TUDelft had been educated primarily during the Modern period, following the tracks of Herman Hertzberger, Aldo van Eyck, or Jaap Bakema, and the influence of teachers like Kees Vollemans and Wim Nijenhuis.

${ }^{10}$ NIO Architecten: 02 Design Peak, (2010).

${ }^{11}$ Nio is locally known for his translation of Baudrillard's book Amerique.

${ }^{12}$ NIO Architecten: 02 Design Peak, (2010).
}

implicit. ${ }^{13}$ Herein lies the origin of the "creatures" Nio produced in following years. The diffused mistrust of orderly views of the world that was an inheritance of the undermining doubts of the seventies, along with the new anxieties of the Dutch architects ${ }^{14}$ at the doorstep of the nineties, created a fertile environment in which Nio could develop his own architecture. Unlike such colleagues as Ben van Berkel or MVRDV, who sought an architecture of affirmation and clear statements, Nio elected to cope with the generic panorama by playing with ambiguity and contradictions.

\section{Disquieting presences: seeking an identity}

From incinerators to movable bridges, from flyovers to sound-barrier housings, a common aspect can be discerned within the overall work of Maurice Nio, namely, a continuous quest to determine new identities, yet in an ambiguous way, emerging from a supposed default genericness. Based on his cultural framework, he seems to react to the elusive, anonymous built environment by means of emphasis. His characters have an extreme, loud identity, standing up from the flat horizon of the contemporary architecture of modern (Dutch) cities. The creation of new, factious identities hinges on two main aspects: contradiction (within reality and context) and ambiguity.

Contradictions have been powerful leverage throughout the Postmodern period, devices capable of unveiling the fallibility of the interpretative tools with which we face reality, ${ }^{15}$ resulting in such architectural positions as that of Venturi (1977) or even of Koolhaas (1995), most of whose literary work involves pragmatically unmasking the contradictions of contemporary consumerist society (Prestinenza Puglisi 2004, p. 104). The more Modern ideas sought to define and control reality and the built environment, configuring these as something technically measurable, the more the Postmodern reacted by undermining established certainties. The characteristics Nio inserted in the city may be conceived within this strand, as a sudden presence whose characteristics are disquieting, odd and disturbing. They are physical demonstrations of the fact that reality finally cannot be explained or understood. To that end, Nio employs in his projects such visionary entities as animals (with the appearance of beasts); wolves (The Monkfish and the Waterwolf, 2009); birds (Bus station and Park \& Ride in Oristano 2009);

\footnotetext{
${ }^{3}$ Ibidem.

14 Nio finished his studies at TUDelft in 1988, and started his professional practice in 1989, the year Ibelings indicates as the beginning of Superdutch architecture.

15 As is known, Postmodernism has early origins and larger temporal and conceptual boundaries. However, the use of contradiction as an epistemological device referred to herein occurs during the final stages of the period.
} 
whales (the Amazing Whale Jaw, 2003); or flora, as with the White Orchid (2006). He even involves such fantasy forms as the half moon, in the extension of the Museo Pecci in Prato (2016), or "real characters" from the comicbook realm (the X-men 2005, David and the Hulk 2003).

Breaking down the categories (plants, animals, and shapes) of the entities Nio creates, a certain consistent ambiguity within the same type emerges. The animals are wolves, praying mantises, reluctant or ferocious species caught in extremely elegant or proud poses. ${ }^{16}$ Plants and flowers are oversized or deformed, while basic shapes undergo a process of disfiguring, corruption and morphing.

\section{The Amazing Whale Jaw}

The corruption of commonly shared forms or typical mental schemes is not a per se operation. Nio's intention is to dig into the common lieux, to unveil unexpected values: elegance, interest, and poetry from disturbing and intriguing appearances. In the description of his project for the bus stop in Hoofddorp (NL), he elaborates on the notion of technical spaces:

By "technical spaces", we mean those places in the urban landscape where people do not normally hang around, or those that people sometimes cannot enter at all-dumping sites, industrial estates, highways, car parks, tunnels, viaducts, noise barriers and so on. Almost all the projects that we have realized and are working on are related to such technical spaces, and time and again we feel the need to breathe new life into these often vacant, nondescript and frequently purely functional places. Our aim, indeed our strategy, is to provide the soulless with a spirit.

(Topos 2005, p. 29)

The Amazing Whale Jaw (as the bus station is called) originates from an irregular simple shape, stretched over its structural limits, resulting in a central laceration. This rather large polystyrene foam and polyester volume appears to be a slick, tense, bubblegum-like object, whose formal characteristics cannot be associated with its surroundings; hence they take on the appearance of an unclear something from nowhere, which has touched ground here.

The official description of this project reads:

People often wonder about the building's shape and what it represents, and there are a number of possible answers. A correct answer in architectural terms is that it can be viewed as a large boulder that has

\footnotetext{
${ }^{16}$ An anecdote is worth noting: in his office in Rotterdam, Maurice Nio has a stuffed pelican whose beak impends a few centimetres from the meeting table: Every meeting, even the most serious and important, starts with this bizarre yet elegant once-living presence.
}

been worn away by footsteps and sight lines. A correct answer in philosophical terms is that it can be regarded as a form that has not been pored over but which simply allowed itself to be discovered. A correct answer in terms of the designing process is that it can also be explained as a product of this process, which in this case was somewhat intuitive because of the unfamiliar technical terrain in which everyone had to operate. All these answers are simultaneously correct and irrelevant. Like the white face of a geisha, every opinion and image can be projected onto the building and it has no answers of its own. ${ }^{17}$

In both the written description and the built project itself, there exists a common and voluntary lack of clarity. The building channels curiosity through its shapes and composition; it therefore provides a clue to a possible significance through its name, but does not declare it openly. The narratives in Nio's projects are nested, subtly suggested, but never definitively explained. There is an intention of declaring a statement, but it is immediately confounded or confused by means of different interpretations. All Nio's projects are allusive, indeterminate and therefore ambiguous and disquieting at the same time, with special emphasis on those cases in which the context may be reassembled into a generic urban panorama. As Nio, says, "We designed the building in the tradition of Oscar Niemeyer, as a cross between white modernism and black Baroque". 18

\section{The Fire Emperor}

A second exemplary project is The Fire Emperor-the competition for Rotterdam's new market hall launched in 2004. The project deals with the subject of food and, typically of Nio, it has been broken down into all its possible configurations. Food has been lately analysed by Nio and his team in the research "Eat This!", later to become a book of the same title (Nio and Almekinders 2006). The research investigated several ways of preparing and consuming food, but also explored such lateral questions, related to eating, as advertising, packaging and even sex. The Fire Emperor originates from the same intention of looking at food from a broad perspective, which would eventually reappear in Eat This! Food is not intended as a natural element in people's lives, placed in balance with other needs and the rest of the world. Instead, it emerges as a distorted presence, taking over the entire life space. This depiction is translated into spatial terms by the internal renderings of the proposed market hall, where animals greedily consume

\footnotetext{
${ }^{17}$ From the official project fact sheet, published on the Nio Architecten website (Accessed on Feb. 1, 2013). The same description appeared in several publications, including NIO Architecten: 02 Design Peak (2010, p. 58) and Carta (ed.) (2012, p. 134).

${ }^{18}$ Maurice Nio, Bus Station in Hoofddorp, in (Topos) n. 53, Dec. (2005, p. 29.)
} 
raw foods, where fruits and other vegetables are piled up in enormous stacks, and where food is, in general, merged with random people or savage animals (monkeys, snakes or pelicans). The project hinges on images of a world deformed by the presence of food in all its declinations and all its possible forms. Nio describes the project thus:

The supply of food and drink are often a reason to go out of the house, into the city. Everybody has to eat every day. For some, this daily routine of buying, cooking and eating has even become a ritual. All these routines and actualities we want to bring closely together, so the intimacy and cultural richness of the food become clearer, more visible. That is where the public and the private life can tolerate each other wonderfully. ${ }^{19}$

Moreover, the imagery employed to present this concept is relevant to this discussion. Images are purposely rendered blurry, out of focus or hazy. Food consumption is alluded to in terms of effects which recall alcohol or drug intake, and is not here presented as a negative or a positive question, but simply displayed through a magnifying glass, emphasizing the possible effects of food's exaggerated consumption and presence in daily life.

\section{AVI Twente}

One of the most peculiar aspects of Nio's entire production lies in his interest in "side projects"-that is to say those leftover urban spaces resulting from infrastructure and urban centres and inherited from the modern city (e.g. Koolhaas' Junkspace, 2006): tunnels (I'm no Angel, The Monkfish and the Waterwolf, Moon Knight, Touch of Evil, X-Men); bridges (Prayer of Shadow Protection or The Acquarians); or buildings in nested locations (Heaven and Hell or The Cyclops). The Afval Verbrandings Installaties (AVI) Twente, a waste incinerator plant in Hengelo, can be considered within this taxonomy. The name chosen for this project is The Hulk. ${ }^{20}$

In its year of completion, the project was widely, yet locally, reviewed and presented for its ambiguous appearance and mysterious aura. Arthur Wortmann described it as "an insect-like, articulated object with an unmistakable inner life" (Wortmann 1997, p. 43). The

\footnotetext{
${ }^{19}$ From an interview with the author.

20 The name of the project closes the circle by compressing all the phases within a meaning suggested by a name. The name was of course not coined by the architect: He needs his project to refer to a story which already exists as embodied in its title. The name thus stands for the meaning that Nio wants to confer upon the project. Each name is thus chosen for its evocative power. The Incredible Hulk, named for the Marvel Comics character, suggests the features of the Waste Incinerator: an enormous monster that performs such superhuman feats as pulverizing and consuming garbage. ("Hulk crush!" the character says in the Hollywood movie.) The monster is-obviously-lit by strong green lights.
}

direct analogy to the insect seems predominant also in Janny Rodermond's review: ${ }^{21}$

The effect of the green colour of the metallic aluminium coating can easily be associated with insects. Together with the indefinable shape, it determines the ambiguous, multi-interpretable character of the building. Depending on the weather and the brightness, it sometimes shines like a jewel, a disturbing shiny. (Rodermond 1997, p. 41).

However, the references to the out-of-scale insect in the landscape are ambiguous and contaminated by the intention of being contradictory to the perception of the building:

Contradiction is not literally translated into form. It can also be obtained by a complex game of perceptions, where a discrepancy occurs between the way something appears and what it actually is. This is the strategy used in the Nio AVI-Twente. (Rodermond 1997, p. 42)

In introducing Nio's project, Bart Lootsma (1997) recalled a few of Baudrillard's sentences from Les Stratégies Fatales (translated into Dutch by Nio himself a year before $)^{22}$ :

To the truer than true, we will oppose the falser than false. We will not oppose the beautiful to the ugly, but will look for the uglier than ugly: the monstrous. We will not oppose the visible to the hidden, but will look for the more hidden than hidden: the secret. (Baudrillard and Fleming 1983)

The "disturbing rationale" able to make "poetry out of trash" (Rodermond 1997, p. 42) seems to have its roots in the consciousness of belonging to an inexplicable reality, where there is no longer a "true" or "false", and where absolute values are substituted by excesses (monstrous or secret) and exaggerations that perform the continuous operation of breaking certainties in order to unveil something which appears to be beyond what is seen and understood.

\section{A possible phenomenology}

Based on the three projects here presented, that for the sake of this study epitomise Nio's entire production, an array of recurring aspects emerges.

(a) Projects hinge on a main (visual or mental) image, which is often used as a reference for the prelimi-

\footnotetext{
${ }^{21}$ Janny Rodermond, "Duck of Decorated Shed", in de Architect, n. 7, (1997), pp. 40-47. The review is published in Dutch and English translations from the author.

22 cf. Baudrillard, J., Nio, M. and Vollemans, K. (Translators). De fatale strategieën. Duizend \& Een. (1985).
} 
nary phases of the design, and which re-emerges at the end of the process, in order to explain the final appearance of the building, as well its title. In this regard, Nio explains, "Projects are stories, like films dealing with a narrative line". ${ }^{23}$ This initial image ${ }^{24}$ (representing a story) is commonly associated with others or different subjects, via the employment of metaphors, similes or analogies. Images are then deformed, exaggerated, disfigured and then semantically or visually merged, overlapped or simply juxtaposed, as in the Fire Emperor.

(b) Images originate from flora, fauna or a fantasy background, encompassing animals, flowers, plants or superheroes.

(c) The character of these images, as well as what they reference, is unclear and purposely left ambiguous, as explained in the architect's comment on "The Amazing Whale Jaw" section.

(d) This ambiguity is reflected also at the level of the final appearance, resulting in a confused overall idea of the project (Rodermond 1997, p. 42).

(e) The final resulting image, at the end of the project, is so wide open as to become almost generic. Upon this vagueness, it becomes quite difficult to address a sharp opinion or comment, while the final result allows for multiple interpretations and diverse (general and subjective) ideas.

(f) Images drawn from natural or fantasy ecology are, in the shadow of Baudrillard, dramatized up to the boundaries of their recognisability.

(g) In fact, the line of thought traced by Baudrillard in Les Stratégies Fatales seems to be a recurrent idea in Nio's work, driving his original (design) images into a constant overstatement of his works: The food is explained in its absurd relationship with consumers in the Fire Emperor, while the shape of The Amazing Whale Jaw is stretched over its physical limits and the AVI Twente turns a massive waste plant into a "cathedral" (Nio 2004, p. 46).

(h) Nio's projects seem to have no pretensions of being understood, nor remembered, seeming rather to emerge from the contemporaneous, to offer timeless statements.

\footnotetext{
${ }^{23}$ From an interview with the author, January 2011.

${ }^{24}$ Maurice Nio explains concerning the genesis of a project that there is not really a start. The projects were already started. We just jumped in, on a moving train. If we are lucky we find an image we can hold on to, but most of the time we are puzzled and lost in the process. If we are lucky we understand the project when it is built, but sometimes we still cannot grasp its meaning. We can communicate with clients and contractors (of course) but we do that in the language which everybody understands. (From an interview with the author, January 2011).
}

The above-mentioned aspects can be summarised as follows. Nio's work:

(a) plays with similitudes and metaphors by merging them

(b) employs naturalistic and surreal imagery

(c) embodies ambiguous references

(d) is visually ambiguous

(e) induces speechlessness

(f) employs forms based on known images (animal, flora), but deformed to the limit of the recognisability

(g) works as Fatal Strategies

(h) is meant primarily to be a wakening splash in the face (no pretension of replacing monuments/historical place of worship).

\section{Conclusions: A possible drifting away from iconic architecture?}

It may be an editorial coincidence that the AVI Twente review by Lootsma was published in (1997) in Domus, in the pages immediately following the Koolhaas essay "The Generic City". However, this serendipity, after 15 years, provides readers another clue as to that vibrant characteristic of uncertainty in which these facts were unfolding. At the same time as Koolhaas was trying to define the ultimate effects of globalisation on the city, identifying an alarming loss of identity, several architects (including the same Koolhaas) were reacting to this apparent flatness of architecture by elaborating what has lately been called iconic architecture.

When the phenomenology proposed above for the work of Maurice Nio is compared to Jencks' description of iconic architecture, it emerges that Nio's production adheres to Jencks' description only partially:

\section{Iconic architecture (Jencks' enig. Nio's work (according to "A pos-}

sign.) sible phenomenology" section)

(a) applies metaphors as a dominat- (a) plays with similitudes and metaing aspect phors by merging them

(b) conveys naturalistic and cosmic (b) employs naturalistic and surreal imagery imagery

(c) embodies cosmic references

(d) has visual (layered) ambiguity

(e) provokes verbal evidence

(c) embodies ambiguous references

(f) is not freeform, nor completely usual

(d) is visually ambiguous

(e) provokes speechlessness

(f) bases forms on a known image (animal, flora), but deformed to the limit of recognisability

(g) work as (Eco's) "Open Work" (g) works as a Fatal Strategie

(h) are fit for worship the face 
As an architect educated at the end of the Postmodern period, with genericness as a primary characteristic of his presences, Maurice Nio has worked during the same period as his (super) Dutch colleagues. Yet, unlike themconstantly proposing new identities and paradigms, seeking positive design solutions-Nio has reacted to the flattened architectural panorama in a less assertive way, and has sought to explain his peculiar design approach by introducing the notion of sovereignty:

The opposite to identity is not genericness but sovereignty. Is it possible to sidestep the contract between wholeness and totality, and to speak of a pact between the sovereign and the singular? About a pact between people and things? About a codified relationship which is indeed ambiguous? About the relation between the residents of Hengelo and their eccentric "cathedral", dedicated to their own waste matter? (Nio 2004, p. 46)

It is relevant to note that Nio does not consider identity and genericness to be antinomies. In order to resolve this relationship (both semantically and conceptually), he seeks to introduce an infinite distance between people and objects by employing a third question: that of sovereignty. This concept describes a form that is "too heavily determined by non-human forces" (Nio 2004, p. 43) to allow for human recognition (something that is, by contrast, possible for identity). Sovereignty is a supreme power embedded in objects that cannot be deeply understood. Recalling this notion, Nio ensures for his projects an aura of ambiguity in appearance and in one's spatial experience of them. The Baudrillardian ambiguity which configures Maurice Nio's work emerges through a family of monsters inspired by flora, fauna and inanimate objects - an entire world of presences created to disturb tranquillity and constantly raise questions and doubts about the way we see reality every day.

\section{Competing interests}

The author declares that he has no competinginterests
Received: 29 July 2016 Accepted: 20 September 2016

Published online: 29 September 2016

\section{References}

(2005) TOPOS - international review of landscape architecture and urban design. 53:29

Betsky A (2003) MVRDV: The Matrix Project. In: Patteeuw V (ed) Reading MVRDV. NAi Publishers, Rotterdam, pp 10-23

Augé M (1992) Non-lieux: introduction à une anthropologie de la surmodernité: Seuil

Baudrillard J, Fleming J (1983) Fatal strategies. Grasset, Paris

Baudrillard J, Nio M (1985) De fatale strategieën: Duizend \& Een

Carta S (2012) Urban Presences, Maurice Nio 2000-2011. AADCU Publishers, Beijing

Eagleton T (1996) The illusions of postmodernism: John Wiley \& Sons

Harvey D (1989) The condition of postmodernity (Vol. 14): Blackwell Oxford

Ibelings H (1998) Supermodernism: Architecture in the age of globalization: Nai Uitgevers Pub

Jameson F (1991) Postmodernism, or, the cultural logic of late capitalism: Duke University Press

Jencks C (1978) The language of post-modern architecture. Rizzoli, New York Jencks C (2005) The iconic building: Rizzoli New York

Koolhaas R (1995) The generic city SMLXL. The Monacelli Press, New york Koolhaas R (1996) "From Bauhaus to Koolhaas," interview in Wired 4.07. http:// www.wired.com/1996/07/koolhaas/last. Accessed 01 Sept 2016

Koolhaas R (2006) Junkspace. Quodlibet, Macerata

Lootsma B (1997) Inceneritore per rifiuti, Twente, Olanda. Domus (791), 14-23

Lootsma B (2001) SuperDutch Afterthoughts Post. Rotterdam. Rotterdam: 010 Publisher

NIO Architecten: 02 Design Peak. (2010). Seoul: Equal books.

Nio M (2004) Unseen I Slipped Away Rotterdam: 010 Publishers

Nio M, Almekinders J (2006) EAT THIS! Het kookpunt van publiek domein. Amsterdam: 1001 publishers

Prestinenza Puglisi L (2004) Rem Koolhaas: A moral amorality. In: Costanzo $M$, Ibelings $H$ (eds), Dutch touch. In: On the second Modernism in the Netherland, pp 104-115. Kappa, Rome

Rodermond J (1997) Duck of Decorated Shed: Afvalverbrandingsinstallatie aviTwente van Maurice Nio. ARCHITECT-DEN HAAG 28:40-44

Rossi A (1976) La città analoga: tavola. Lotus 13 Internacional, 5-9

Tschumi B (1989) De-, Dis-, Ex-. In: B. Kruger (Ed.), Remaking History. Seattle: Bay Press

Venturi R (1977) Complexity and contradiction in architecture (Vol. 1): The Museum of modern art

Virilio P (1983) La ville surexposée. L'espace critique

Wortmann A (1997) Vorm en inhoud. De AVITwente van Maurice Nio. Archis (4):42-43 